\title{
Redescription of larva, pupa and adult of Anopheles (Anopheles) annulipalpis (Diptera: Culicidae) and the removal of the specie of the Cycloleppteron Series
}

\author{
Gustavo C. Rossi \\ Centro de Estudios Parasitológicos y de Vectores (CEPAVE), CCT La Plata, CONICET - UNLP. Boulevard 120 entre 61 y 62 (1900) La Plata, Argentina. \\ (gustavo@cepave.edu.ar)
}

Received 18 July 2015

Accepted 12 May 2017

DOI: $10.1590 / 1678-4766 e 2017025$

ABSTRACT. The redescription of male, female, pupa and larva of Anopheles (Anopheles) annulipalpis Lynch Arribálzaga, 1878 is presented. The species is included in the Cycloleppteron Series of Anopheles, although several authors consider that this is artificial. The redescription of Anopheles annulipalpis demonstrate that pupae have laticorn trumpet. By this fact is compared with An. grabhamii Theobald, 1901 and similar species of the Arribalzagia Series and Myzorhynchus Series. The laticorn type of trumpet joined the other differences and similarities found are sufficient to remove An. annulipalpis of Cycloleppteron Series and included as an unplaced member of the Angusticorn Section.

KEYWORDS. Anophelini, mosquitoes, Neotropical, taxonomy, Argentina.

Anopheles annulipalpis Lynch Arribálzaga, 1878 is a Neotropical species. The description of adult, pupa and larva are incomplete for the current status of Anophelinae. LYNCH ARRIBÁLZAGA (1878) described the species based on a female. BRÈTHES (1912) made a brief description of the male, later in 1916 he published a drawing of the male genitalia. Shannon \& Del Ponte (1928) commented on this matter, and redescribed the female. DYAR (1928) described the female. Alvarado \& Del Ponte (1938) described the larva with specimens collected in Mendoza province, more than $850 \mathrm{~km} \mathrm{~W}$ of the type locality. Del Ponte (1940) presented a new description of the male genitalia with specimens of the Delta del Paraná in Entre Ríos province. GARCÍA \& CASAL (1964) described the pupa of An. annulipalpis from the same area. ROMEO Viamonte \& CASTRO (1951) described the cibarial armature of female. EDWARDS (1932) and LANE (1953) includes An. annulipalpis in the Cycloleppteron Series of the Angusticorn Section of Anopheles (Anopheles). Subsequently, ReID \& KNAB (1961) proposed only two species in the Cycloleppteron Series (An. grabhamii Theobald, 1901 and An. annulipalpis). This classification adopted by Wilkerson \& Peyton (1990) and Harbach (1994). Later, Collucci \& SAllum (2007) and Harbach \& KITCHING (2015) demonstrated the Section Angusticorn and the Series Cycloleppteron to be artificial groups within the subgenus Anopheles.

The objective of this study is the redescribe the male, female, pupa and fourth-instar larva of An. annulipalpis, update the nomenclature and compared it with the most similar species as An. grabhamii, An. punctimacula Dyar \& Knab, 1906, An. shannoni Davis, 1931 (Arribalzagia Series), An. coustani Laveran, 1900, An. tenebrosus Donitz, 1902 and An. sinensis Wiedemann, 1828 (Series Myzorhynchus) for being the most similar species of Anopheles.

\section{MATERIAL AND METHODS}

Morphological structures were examined in the adult, pupa, and fourth-instar larval stages. Diagnostic and differential characters were confirmed in all specimens listed in the Material examined section. The morphological nomenclature follows HARBACH \& KNIGHT $(1980,1982)$. Abbreviations of generic level are taken from REINERT (2009).

Morphological data of species used in the comparation were taken from BELKIN et al. (1970) (An. grabhamii), WILKERSON et al. (1997) (An. shannoni), WILKERSON (1990) (An. punctimacula), Gillies \& De MeIllon (1968) (An. coustani, An. tenebrosus), Harrison \& SCANLON (1975) (An. sinensis), and the data set of HarbaCH \& Kitching (2005) and CollucCi \& SAllum (2007).

Life stages are indicated by the symbols $\widehat{\partial}$ (male), ㅇ (female), L (fourth-instars larva), Le (larval exuviae), and $\mathrm{Pe}$ (pupal exuviae), and male and female genitalia are denoted by the letter $\mathrm{G}$ (genitalia) used in combination with the respective sex symbol. A total of 76 specimens were examined. Measurements are in millimeters, the minimum and the maximum values followed by the mean between brackets; counts and ratios are similarly formatted. Adults 
were pin mounted, genitalia, head and immature were mounted between slide and coverslip with Canada balsam. Voucher specimens were deposited in La Plata Museum (MLP), Argentina. Latitude and longitude data of the collecting locations were taken from Google Earth.

Specimens that were examined are the following: 7 males, 4 male genitalia, 54 females, 2 female genitalia, 7 pupal exuviae (reared to adult), 2 larval exuviae (reared to adult), 6 larvae, 3 female wing. All specimens are deposited in División Entomología, Museo de La Plata.

Material examined. ARGENTINA, Salta: Tartagal

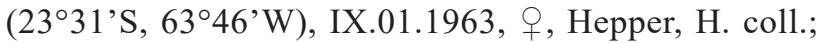

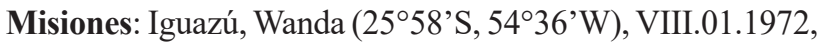
$3 \bigcirc$, MLP coll; Mendoza: Uspallata, Potrerillos, río Mendoza (3256'59'S, 69¹1'49”'W, 1370 masl), II.27.2002, 4우, Scheibler, E. coll.; Entre Ríos: Concepción del Uruguay

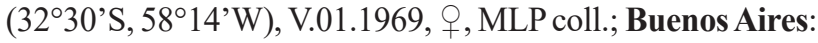
Berisso, Los Talas (3453'17’'S, 5749'31'W), II.10.1988, †, García, J. J. coll.; idem, VIII.18.1988, †, Spinelli, G. coll.; idem, IX.06.1988, क, Marino, H. coll; XI/15/1988, , Marino, H. coll.; La Plata, Observatorio Astronómico (3454'27'S, 5755'57’'W), IX.10.1991, ㅇ, Maciá, Campos coll.; Magdalena Arroyo Zapata y RP 11 (35'3'38'S, 57³7’41”W), IX.06.1988, 2o, Armesto, Marino coll.; idem, XI.29.1988, 29, Marino, H. coll.; Ensenada, Punta Lara, Reserva (3447'23”'S, 580'01'W), XI.11.1985, 2 \%, Balseiro, E. coll., R. Ronderos det.; idem, VIII.08.1989, ๆ, Maciá, Campos coll. and det.; idem, VIII.14.1989, \&, Rossi, Maciá coll.; idem, VIII.29.1989, + , Maciá, Campos coll. and det.; idem, IX.25.1989, 3 우 , wing, 1 L, García, Rossi, Maciá, Campos coll.; idem, X.23.1989, ㅇ, Maciá, Campos coll.; idem, XI.06.1989, 2へ̂, 2우, ㅇ wing, Maciá, Campos coll.; idem, V.01.1990, 7우, ㅇ wing, Maciá, Campos coll.; idem, VIII/21.1990, 2q, $q$ G, Maciá, Campos coll.; Ensenada, Punta Lara, Boca Cerrada ( $34^{\circ} 47^{\prime} 8^{\prime}$ 'S, $58^{\circ} 0^{\prime} 57^{\prime}$ 'W); idem, XII.09.1996, 20̂, 2 đ G, ㅇ, 3 Pe, 2 Le, 2 L, García, J. J. coll.; idem, X.01.1998, 9ᄋ, $\uparrow$ G, Micieli, M. V. coll.; idem, XI.26.2002, 1 L, Micieli, Marti coll.; Ensenada, Punta Lara, Provincial Route 19, $5.5 \mathrm{~km}$ from Boca Cerrada (3449'2”S, 5803'11’'W); idem, V.01.1989, 3 \% , Rossi, coll.; idem,

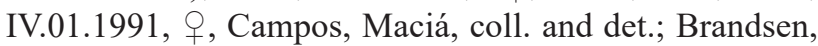
Provincial Route 215 , Brandsen - La Plata $\left(35^{\circ} 05^{\prime} 25^{\prime}\right.$ 'S,

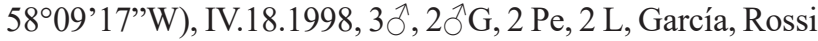
coll.; idem, IV.25.1989, , 2 Pe, García, Campos coll.; Zárate (3406’45’'S, 5859’53”W), XI.20.1998, , , Marino, P. coll.

\section{RESULTS AND DISCUSSION}

\section{Anopheles (Anopheles) annulipalpis Lynch Arribálzaga, 1878}

Anopheles annulipalpis Lynch ArRIBÁlzaga, 1878:149. Brèthes, 1912:13M; 1916:199M*; Alvarado \& Del Ponte, 1938:388L*; Del Ponte, 1940:302MG*; García \& CASAL, 1964:5P*; CAMPos, 1997:31 (biology). Further details about the synonymy are in LANE (1953).

Female. Integument light to dark brown with grayish pollinosity. Head. Interocular space with 8-14 long, and whitish setae and lateral row of small, narrow, appressed white to light cream scales; vertex and occiput with whitish erect scales, dark scales posteriorly, upper portion of postgena with erect, truncate black scales; head with 6-8 long, dark ocular setae; postgena with long black setae ventrally. Clypeus bare. Pedicel of antenna with several small, narrow to broad, grayish white spatulate scales dorsolaterally; flagellomere 1 with several narrow to broad whitish scales on lateral surface and a few whitish scales on inner surface; flagelomeres 2-7 with patch of whitish scales on lateroapical surface. Scales of maxillary palpus slender, spatulate, dark brown with intermixed dark brown setae; palpomere 2, covered with erect dark and whitish erect scales intermixed in inner side of dorsal surface of basal half and at apex, palpomere 3-5 decreasing in size, dark scales, with whitish basal ring, 3-4 with intermixed whitish scales in dorsal and outer sides, 5 dark-scaled, sometime with whitish scales at apex, sometimes with whitish scales on middle of outer side of palpomere; length of maxillary palpus $2.40-2.85 \mathrm{~mm}$ (mean $=2.59$ $\mathrm{mm}$ ); palpus longer than forefemur length. Proboscis darkscaled, base with long erect scales and setae; proboscis length 2.40-2.95 mm (mean = 2.74 mm). Thorax. Scutum grayish brown, with three longitudinal pruinose lines, covered with small whitish scatered scales, two bare areas widen gradually posteriorly from posterior scutal fossa to scutellum. Acrosticals, anterior and posterior dorsocentral bristles dark brown. Anterior promontory, lateral scutal fossa ante- and supralar areas with spatular white scales. Scutellum with 16 (13-18) long dark brown setae, about 40 short, light brown setae, these with golden reflections and whitish spatular scales. Antepronotum with dense patch of dark brown spatulate scales and long, strong brown setae and a patch of whitish scales on lower. Antepronotum Pleural vestiture as follows: all scales whitish translucent, spatulate. Proepisternum sometimes with 2,3 scales; upper proepistemum with 4-6 setae of different length; prespiracular area with 2,3 setae, rarely with 1,2 scales; prealar area with 3-7 setae; upper mesokatepisternum with $1(1,2)$ setae, 4-6 $(n=10)$ translucent scales; lower mesokatepistemum with 3-6 setae, 5-9 scales; upper mesepimeron with 5-9 setae, scales absent. Legs. Forecoxa with upper patch of black scales on anterior surface, and a patch of long, erect whitish scales posterolaterally; foretrochanter mostly with small appressed white scales posteriorly, midcoxa with three patches of white scales, hindcoxa with one patch of whitish scales, mid- and hind trochanters with patches of whitish scales. Extent and number of pale spots on femur and tibia variable. Forefemur rather whitish scaled ventrally; mid- and hindfemur with ventral stripe of whitish scales with well demarcated borders, extending on almost entire length of femur; foretibia darkscaled, with white spots extending to ventral and dorsal surfaces, midtibia with ventral longitudinal stripe of yellow scales extending to 0.7 from base, anterior, posterior and dorsal surfaces with spots of white scales, sometimes encircling the tibia, hindtibia dark, with white spots forming a strip from middle to apex internally; foretarsomere 1 dark-scaled with spots of white scales on anterior and dorsal surfaces, fore- 
and midtarsomere 2,3 dark scaled, with spot of white scales anterolaterally at apex, sometimes with one or two whitish spots; foretarsomeres 4 and 5 dark-scaled; hindtarsomeres 1 dark-scaled with spots of white scales on anterior and dorsal surfaces, hindtarsomere 2 dark-scaled with prebasal and apical lateral spots of white scales, hindtarsomere 3 with apical spots of white scales, hindtarsomeres 4 and 5 entirely white-scaled. Forefemur length $2.15-2.40 \mathrm{~mm}$ (mean $=2.28$ $\mathrm{mm}$ ). Wing. Length (measured from humeral crossvein to tip of wing, not including fringe) $4.70-5.70 \mathrm{~mm}$ (mean $=$ $5.21 \mathrm{~mm}$ ). Dark scales brown, pale wing scales whitish. Vein $\mathrm{C}$ dark except by the presence of apical pale spot; humeral cross-vein dark-scaled dorsally and ventrally. Vein SC darkscaled, vein $\mathrm{R}_{1}$ with pale and dark spots very similar to those of the Arribalzagia Series (sensu Wilkerson \& Peyton 1990). Posteriors veins with intermixed brownish, whitish, and dark scales. Vein $\mathrm{R}_{4+5}$ with basal spot of white scales, a small white spot, 6-8 dark scales, remaining of vein palescaled, with 2-12 dark and white spots at apex (in some specimens apex with or without dark scales), vein M mostly whitish-scaled intermixed with only dark scales, preapical end with two brownish spots and one dark spot that continues on proximal veins $M_{1}$ and $M_{2}$, veins $M_{3+4}$ pale-scaled with four and two spots of dark scales respectively, $\mathrm{CuA}$ with pale whitish scales intermixed with dark scales and two patches of dark scales near base and middle of vein, vein $1 \mathrm{~A}$ mainly dark, with mixture of whitish and dark scales at base, alternating with five small, white spots. Fringe brownish, with whitish spots apically at $\mathrm{M}_{3+4}$. Halter. Scabellum with whitish integument, pedicel and capitellum with dark brown integument, without scales. Abdomen. Integument brown to dark brown with some grayish pollinosity. Terga with numerous long yellowish setae; terga without posterolateral scales; tergum VIII with long, yellowish setae and several white, spatulate scales. Sterna with scattered yellowish setae; sternum I with elongated patch of white spatulate scales; sterna II-VII without scales.

Genitalia (Fig. 1): Tergum IX narrow, with small finger-like lobe on each side of median straight line; cerci elongate, somewhat elliptical in outline with dark scales and with numerous long brownish setae; postgenital lobe weakly sclerotized, with small posterior bridge with minute spicules, caudal margin rounded with two strong setae at apex; indistinct insular setae upper and lower vaginal lips indistinct; upper vaginal sclerite well-sclerotized.

Male. As in female except for the following sexual differences. Maxillary palpus $2.43-2.71 \mathrm{~mm}$ (mean $2.65 \mathrm{~mm}$ ), apex of palpomere 3 , and all palpomere 4 and 5 enlarged. Maxillary palpi with dark brown and yellowish scales; base of palpomere 2 with erect scales, basal 0.5 with patch of yellowish scales, a few yellowish scales at apex of dorsal surface; palpomere 3 with patch of pale yellow scales at base and apex and on 0.2 of dorsal surface; palpomere 4 mostly pale yellow, a spot white scales at base; palpomere 5 usually yellowish; setae at tip of palpomeres 4 and 5 mostly yellowish. Proboscis length 2.29-2.40 mm (mean $2.35 \mathrm{~mm}$ ), with small, decumbent, dark brown scales and ventrobasal patch of long, erect, dark scales.
Genitalia (Figs 2-9): ninth tergal lobes (Fig. 9) short, somewhat triangular in outline, widely separated. Dorsal surface of gonocoxite (Fig. 6) with a few scattered, short and moderately long setae, longer on apicolateral area; lateral surface with several slender, fusiform scales; ventral surface with short to moderately long setae, and 3,4 long setae on apical 0.3 and scales on all length. Parabasal setae arising from a protuberance or distinct tubercle, located near 0.30 from base of gonocoxite; most mesal parabasal spine stouter, rodlike with wide sinuous, hooked tip, borne on strong tubercle, the second parabasal seta longer, slender than mesal seta, straight at apex, near 20 short setae in vicinity of parabasal setae on medial side of gonocoxite. Gonostylus (Fig. 6) widened at both ends, with 4-7 setae on dorsal side and row of small setae in the apical 0.7 of lateral side, gonostylar claw short, spiniform and blunt. Claspette (Figs $2,3,7,8)$. Dorsal lobe of claspette long, with three closely appressed setae of increasing length, tip of most lateral seta with apex enlarged and forming a small hook; ventral lobe of claspette less sclerotized, with three apical or subapical setae, most apical longest, the shorter median; remainder of ventral lobe and area between it and dorsal lobe with many evenly spaced prominent short spicules. Aedeagus (Figs 4, 5): Aedeagal leaflets usually 4 (4-5) per side, most mesal leaflets longest and broadest with small serrations on the internal edge, the rest of decreasing size.

Larva (Figs 10-17). Position and development of setae as figured; range and modal number of branches in Tab. I. Head (Fig. 11). Antennal length $0.30-0.35 \mathrm{~mm}$ (mean $=0.33$ $\mathrm{mm})$, tapered toward apex (Fig. 15), 5.88-6.25 $($ mean $=6.0)$ longer than wide, with spicules longer and more numerous in vicinity of seta 1-A; ventral surface with sparse, short spicules; seta 1-A with 12-23 branches, inserted 0.31-0.38 $($ mean $=0.35)$ distant from base of antenna; seta 2-A pointed; 3-A truncate, fringed at apex (not illustrated); 4-A plumose on about apical 0.8 , shorter than $2-\mathrm{A}$ or 3 -A. Seta $2-\mathrm{C}$ single with 2-7 branches arising from 0.3 apical, length 1.0-1.25 (mean $=1.08$ ) length of $3-\mathrm{C}$, seta $2-\mathrm{C}$ close to mate of opposite side, distance between bases $1.5-2.0($ mean $=1.75)$ width base of single seta; 3-C 0.80-1.0 length of 2-C, with 5-10 branches, clypeal index (distance between bases of 2-C and 3-C (Fig. 16) on one side/distance between bases of 2-C) 2.50-3.67 (mean =3.07). Mentum (Fig. 14) usually with four irregular teeth at the sides of the central but larger tooth. Thorax (Fig. 10). Seta 1-P not palmate, always single; 9, 10, 12-P single, 11-P single or double; 9-12-M single, 12-M 0.3 length of 9, 10-M, 11-M very short; 3-T weakly developed, hyaline, palmate; 11 -T very short, $\sim 0.25$ length of $12-\mathrm{T}$, 12-T moderately developed. Abdomen (Fig. 10): Integument hyaline, with minute spicules on ventral surface, more evident on central portion of each segment; setae l-I-VII palmate (Fig. 17), 1-I, II weakly developed, hyaline (not illustrated), leaflets of developed setae broad with jagged margins, apices weakly pigmented. Segment X (Fig. 12): Seta 1-X not inserted on saddle. Saddle with minute, sparse spicules on lateral surface, caudally present a prominent median dorsal caudal process of saddle. Integument of posterior margin of segment $\mathrm{X}$ 

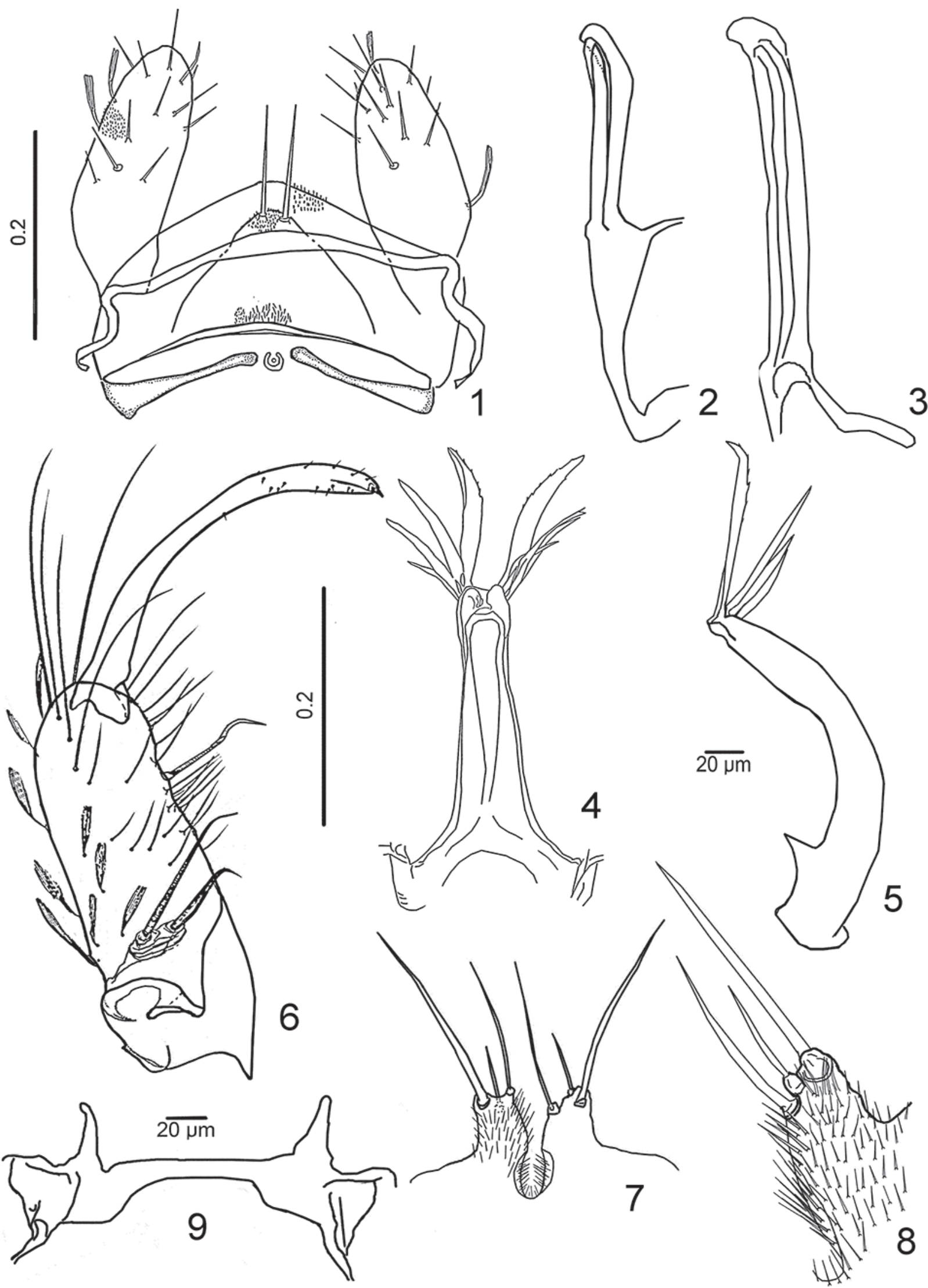

Figs 1-9, Anopheles (Anopheles) annulipalpis Lynch Arribálzaga, 1878. 1, Female genitalia; 2-9, male genitalia: 2, dorsal lobe of Claspette, 3; setae of dorsal lobe of Claspette; 4, aedeagus; 5 , lateral view of aedeagus; 6 , gonocoxite and gonostylus dorsal aspect (prerotation sense); 7 , ventral lobe of Claspette; 8, detail of ventral lobe of Claspette; 9, IX-Tergum. Scales in mm, except when indicated. 
Tab. I. Number of branches for setae of the fourth- instar larva of Anopheles (Anopheles) annulipalpis Lynch Arribálzaga, 1878a .

\begin{tabular}{|c|c|c|c|c|c|c|c|c|c|c|c|c|c|}
\hline & Head & $\mathrm{P}$ & M & $\mathrm{T}$ & I & II & III & IV & $\mathrm{V}$ & VI & VII & VIII & X \\
\hline 0 & & 1 & & & & $3-10(3)$ & $3-9(5)$ & $2-6(4)$ & $4-6(4)$ & $4,5(4)$ & $3-5(4)$ & 1 & \\
\hline 1 & 1 & $1,2(1)^{\mathrm{b}}$ & $\begin{array}{c}17-29 \\
(23)\end{array}$ & $1-3(1)$ & $\begin{array}{c}10-16 \\
(13)\end{array}$ & $\begin{array}{c}10-16 \\
(13)\end{array}$ & $\begin{array}{c}17-26 \\
(24)\end{array}$ & $\begin{array}{c}12-24 \\
(16)\end{array}$ & $\begin{array}{c}16-21 \\
(16)\end{array}$ & $\begin{array}{c}15-24 \\
(16)\end{array}$ & $3-6(5)$ & 1 & 1 \\
\hline 2 & 1 & $8-14$ (13) & $1,2(1)$ & $1-3(1)$ & $6-9(8)$ & $5-8(5)$ & $5-10(9)$ & $2-6(2)$ & $2-5(2)$ & $2-6(6)$ & $4-6(4)$ & $4-7$ (4) & $8-12(11)$ \\
\hline 3 & $6-14(10)$ & 1 & 1 & $5-13(12)$ & $1-3(2)$ & $1,2(1)$ & 1 & 1 & $1,2(1)$ & $1-3(1)$ & $1-6(1)$ & $5-10(7)$ & $3-7(5)$ \\
\hline 4 & $2-6(3)$ & $>11$ & $2-4(2)$ & $1-4(2)$ & $6-9(7)$ & $4-6(5$ & $2-5(4)$ & $2,3(2)$ & $2-4(3)$ & $1-5(1)$ & 1,2 (1) & 1 & 9 \\
\hline 5 & $\begin{array}{c}11-17 \\
(13)\end{array}$ & $>22$ & 1 & $>15$ & $3-8(5)$ & $9-12(9)$ & $5-10(6)$ & $3-7(4)$ & $3-6(5)$ & $3-8(7)$ & $4-9(8)$ & $4-6(5)$ & \\
\hline 6 & $\begin{array}{c}14-19 \\
(15)\end{array}$ & 1 & 1 & 1,2 (1) & 1 & 1 & 1 & $1-3(1)$ & 1,2 (1) & $5-6(5)$ & $6-10(7)$ & & Siphon \\
\hline 7 & $9-17$ (14) & 1 & $2-5(3)$ & $>20$ & 1 & 1 & $4-6(4)$ & $3-7(4)$ & $2-6(3)$ & $3-7(3)$ & $2-6(6)$ & & $\begin{array}{c}1-\mathrm{S}: 3-5 \\
\text { (4) }\end{array}$ \\
\hline 8 & $6-10(7)$ & $7-15(8)$ & $8-15(11)$ & $>18$ & & $1-4(2)$ & $1-4(2$ & $2,3(2)$ & $2,3(2)$ & $2-4(2)$ & $1-4(4)$ & & $\begin{array}{c}2-S: 4-6 \\
(5)\end{array}$ \\
\hline 9 & $3-12(7)$ & 1 & 1 & 1 & $3-7(4)$ & $5-8(8)$ & $3-8(5)$ & $4-6(5)$ & $2-7(6)$ & $5-8(7)$ & $2-6(3)$ & & $\begin{array}{c}6-S: 1,3 \\
\text { (1) }\end{array}$ \\
\hline 10 & $2-7(5)$ & 1 & 1 & $1-3(1)$ & 1 & $2,3(3)$ & $1,3(1)$ & $1,2(1)$ & $1,2(1)$ & $1,2(1)$ & $2-4(2)$ & & $7-S: 1$ \\
\hline 11 & $>35$ & 1 & 1 & 1 & 3 & $-(1)$ & $1-4(2)$ & $1-3(2)$ & $1-3(2)$ & $2-5(3)$ & 1 & & $\begin{array}{c}8-S: 2-4 \\
\text { (3) }\end{array}$ \\
\hline 12 & $3-7(5)$ & 1 & 1 & 1 & $1,2(1)$ & $1,2(1)$ & $1-4(1)$ & $1-2(2)$ & $1-3(2)$ & $1,2(2)$ & $4-8(4)$ & & $\begin{array}{c}9-S: 3-5 \\
\text { (3) }\end{array}$ \\
\hline 13 & $2-9(6)$ & $6-11(9)$ & $3-7(7)$ & $1-4(3)$ & $7-11(8)$ & $8-11(10)$ & $7-11(7)$ & $2-6(3)$ & $2-5(4)$ & $6-11(7)$ & $4-6(4)$ & & \\
\hline 14 & $1-4(3)$ & $\begin{array}{c}10-15 \\
(14)\end{array}$ & $9-12(10)$ & & & & 1 & $2-4(3)$ & $2-3(3)$ & $2-4(3)$ & 3 & $1-2(1)$ & \\
\hline 15 & $3-7(3)$ & & & & & & & & & & & & \\
\hline
\end{tabular}

a: based on nine specimens.

b: range (mode)

with several, strongly developed, dark spicules. Spiracular apparatus (Fig. 12). Pecten plate (Fig. 13) with 15-19 teeth; arrangement of teeth alternating long and short, with 4-6 long and 9-13 short; long spines 2.93-4.47 $($ mean $=4.07)$ about twice length of short spines.

Pupa (Figs 18-20). Position and development of setae as figured; range and modal number of branches in Tab. II. Integument weakly pigmented, with variably pigmented pattern of dark areas and bars on wing case, slightly darker on leg cases, antennal case with dark pigmentation at flagellomere joints; mesothoracic wings light brown with dark areas; abdominal segments weakly pigmented, usually dark at anterior middle. Cephalothorax (Fig. 18): trumpet (Fig. 20) laticorn tragus well developed, elongate; secondary cleft present. Setae 1-3-C single, 1, 3 shorter than 2-CT, setae 4, 6, 7-CT single, 5, 6-CT longer than 4, 7-CT, 5 double, 8, 9-CT single, short. Metanotum (Fig. 19): Setae 10, 11, 12 increasing in size, single, 11-CT usually triple. Abdomen (Fig. 19) with terga and sterna II-VII mostly covered with minute spicules. Seta 6-II single, sometimes double. Terga V-VII with small spicules on caudal border. Genital lobe $0.25-0.28 \mathrm{~mm}$ in male and near $0.17 \mathrm{~mm}$ in female. Abdominal segments III-VII with ventral fold line. Setae 0-II-VII near 0.07-0.20 $\mathrm{mm}, 0$-VIII near $0.04-0.06 \mathrm{~mm}$. Setae $0-I V-V 0.80$ length of 2-IV-V. Setae 9-II-VIII peg-like to long and blunt, 9-II minute, unpigmented, 9-III-VII stout, increasing in size caudally, 9-VIII peg-like, branched (2-9), shorter than 4-VIII. Paddle weakly pigmented, external buttress, base of midrib and base of paddle usually darker, length $0.76-0.95 \mathrm{~mm}$ (mean $=0.82$ $\mathrm{mm}$ ), width $0.53-0.79 \mathrm{~mm}$ (mean $=0.62 \mathrm{~mm})$, somewhat rounded in outline; length of marginal spicules $0.03-0.07$. Seta 1-Pa usually triple, 2-Pa single, 0.5 length of 1-Pa.

Bionomics. Larvae and pupae of An. annulipalpis from Buenos Aires province were collected in large swampmarshy depressions with grasses, sunlight, $\mathrm{pH}$ between 5.50 and 6.79, together with larvae of An. albitarsis Lynch Arribálzaga, Aedeomyia squamipennis (Lynch Arribálzaga), Culex idottus Dyar, Cx. brethesi Dyar and species of Mansonia, Psorophora and Uranotaenia (CAMPos, 1997). Mendoza adults were reared from larvae collected near puddles or pools with water from the derivations of the river, which were scarcely covered with grass and aquatic macrophyta or with no vegetation. Larvae were found in association with Cx. cuyanus Duret and other macroinvertebrates such as Aeshnidae (Odonata), Chironomidae (Diptera), Corixidae (Hemiptera), Hydrophilidae (Coleoptera) and Hyallelidae (Crustacea). The pools have a maximum depth of $0.5 \mathrm{~m}$, the water temperature was $16^{\circ} \mathrm{C}$ (April) and $20.7^{\circ} \mathrm{C}$ (February), pH between 6.77 and 7.57 (Rossi et al., 2006).

The adults of An. annulipalpis are known principally by the descriptions of LYNCH ARRIBÁlZAGA $(1878,1891)$ and Del Ponte (1940), the larva by a brief description (Alvarado $\&$ Del Ponte, 1938) and the pupa by the description of one exuviae by GARCía \& CASAL (1964).

Based on this redescription is observed that certain morphological characters of An. annulipalpis separate it from An. grabhamii - both included in the Cycloleppteron Series (Tab. III) - and it should be included on one of the Series of 


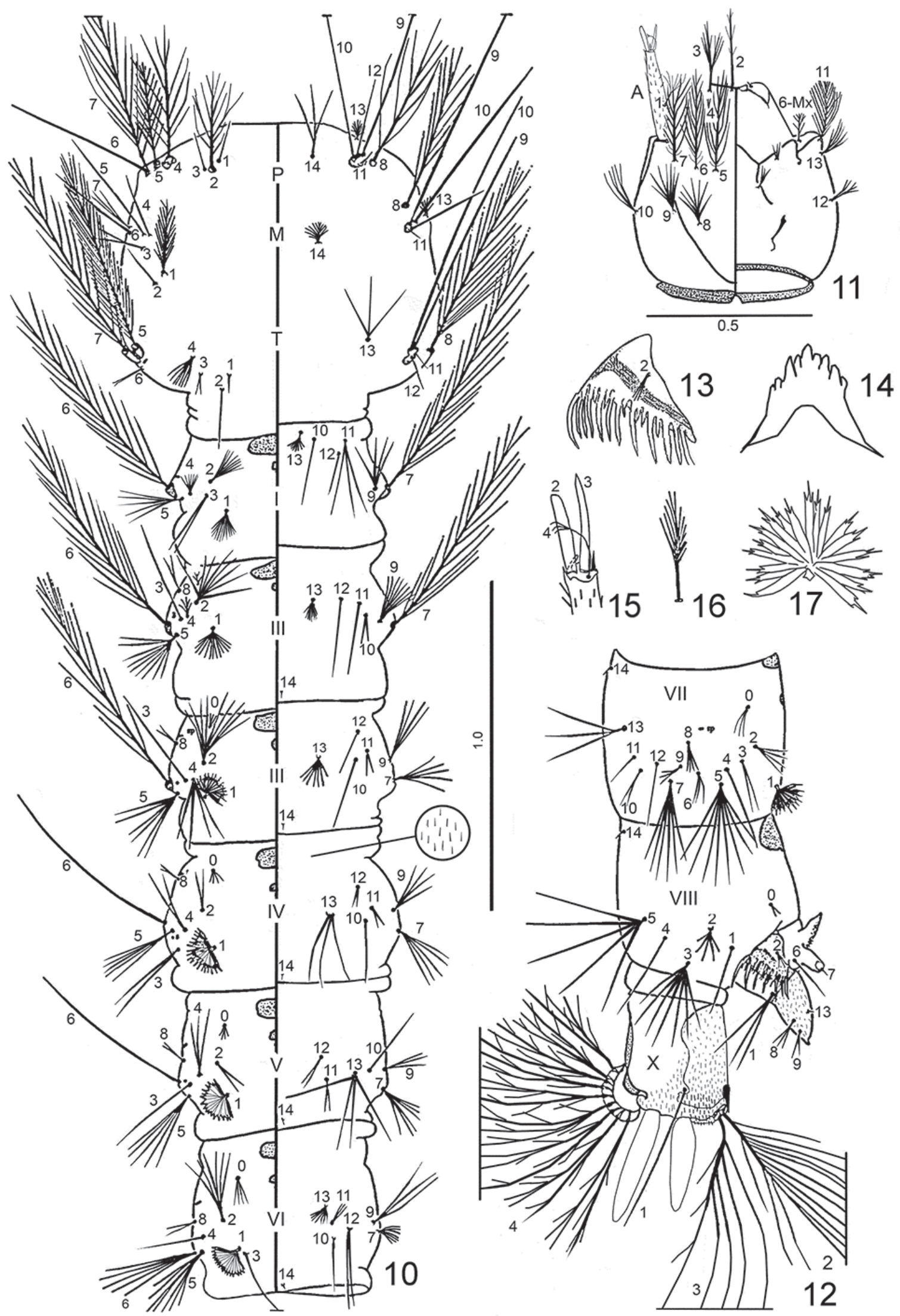

Figs 10-17, Anopheles (Anopheles) annulipalpis Lynch Arribálzaga, 1878, larva: 10, pro- (P), meso- (M) and metathorax (T), and abdominal segments I-VI (left side dorsal, right side ventral); 11, head, left dorsal side, right ventral side; 12, abdominal segments VII-X lateral view; 13, pecten plate; 14, dorsomentum; 15 , detail of antenna; 16, seta 3-C alternative; 17, seta 1-III. Scales in mm. 

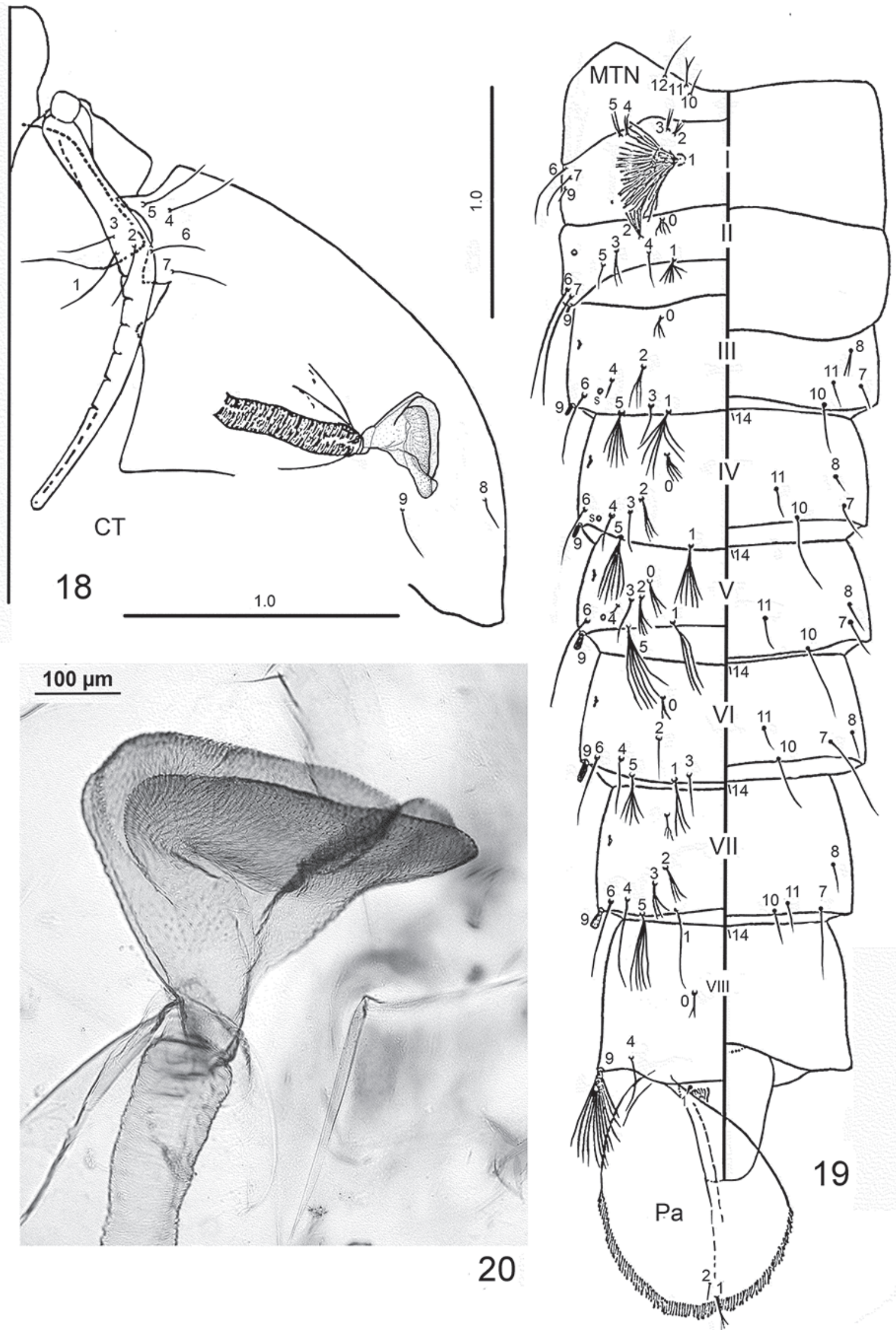

Figs 18-20, Anopheles (Anopheles) annulipalpis Lynch Arribálzaga, 1878, pupa: 18, CT (cephalothorax); 19, MT (metathorax) and abdominal segments I-VIII (left side dorsal, right side ventral); 20, pupa trumpet; Pa. (paddle). Scales in mm except, when indicated. 
Tab. II. Number of branches for setae of the pupa of Anopheles (Anopheles) annulipalpis. ${ }^{\mathrm{a}}$

\begin{tabular}{|c|c|c|c|c|c|c|c|c|c|c|c|}
\hline Seta no. & $\mathrm{CT}$ & I & II & III & IV & $\mathrm{V}$ & VI & VII & VIII & $\mathrm{X}$ & $\mathrm{P}$ \\
\hline 0 & & & $1-4(2) b$ & $2-7(3)$ & 4 & $4-6(5)$ & $2-4(4)$ & $2-4(3)$ & $2-4(2)$ & & \\
\hline 1 & 1 & $12-16(14)$ & $5-9(6)$ & $4-6(6)$ & $4-6(5)$ & $3-5(3)$ & $1-3(3)$ & $1-3(2)$ & & 1 & $1-3(3)$ \\
\hline 2 & $1-2(1)$ & $2-3(2)$ & $3-7(4)$ & $3-4(3)$ & $2-4(3)$ & $1-4(3)$ & 3 & $1-3(3)$ & & & 1 \\
\hline 3 & $1-2(1)$ & $2-3(3)$ & 1 & 1 & 1 & 1 & 1 & $2-3(2)$ & & & \\
\hline 4 & 1 & $1-4(2)$ & $1-4(3)$ & $1-4(2)$ & $3-4(4)$ & $1-2(1)$ & 1 & 1 & 1 & & \\
\hline 5 & $1-3(1)$ & $1-2(2)$ & $1-4(2)$ & $6-7(6)$ & $3-8(5)$ & $6-8(7)$ & $3-6(5)$ & $2-5(3)$ & & & \\
\hline 7 & 1 & $1-2(1)$ & $1-2(1)$ & $1-4(2)$ & $3-7(6)$ & $1-4(1)$ & $1-2(1)$ & $1-2(1)$ & & & \\
\hline 8 & 1 & & & $1-2(2)$ & $1-2(1)$ & $1-3(1)$ & $1-2(1)$ & $1-2(1)$ & & & \\
\hline 9 & 1 & 1 & 1 & 1 & 1 & 1 & 1 & 1 & $3-9(8)$ & & \\
\hline 10 & 1 & & 1 & 1 & 1 & 1 & 1 & 1 & & & \\
\hline 11 & $2-4(3)$ & & 1 & 1 & 1 & 1 & 1 & 1 & & & \\
\hline 12 & 1 & & & & & & & & & & \\
\hline
\end{tabular}

${ }^{\text {a }}$ Based on counts made on all setae available of 8 specimens; P: prothorax; M: mesothorax; T: metathorax

${ }^{\mathrm{b}}$ Range (mode).

Tab. III. Morphological comparison between An. annulipalpis, An. grabhamii, An. punctimacula, An. shannoni, An. coustani, An. tenebrosus and An. sinensis.

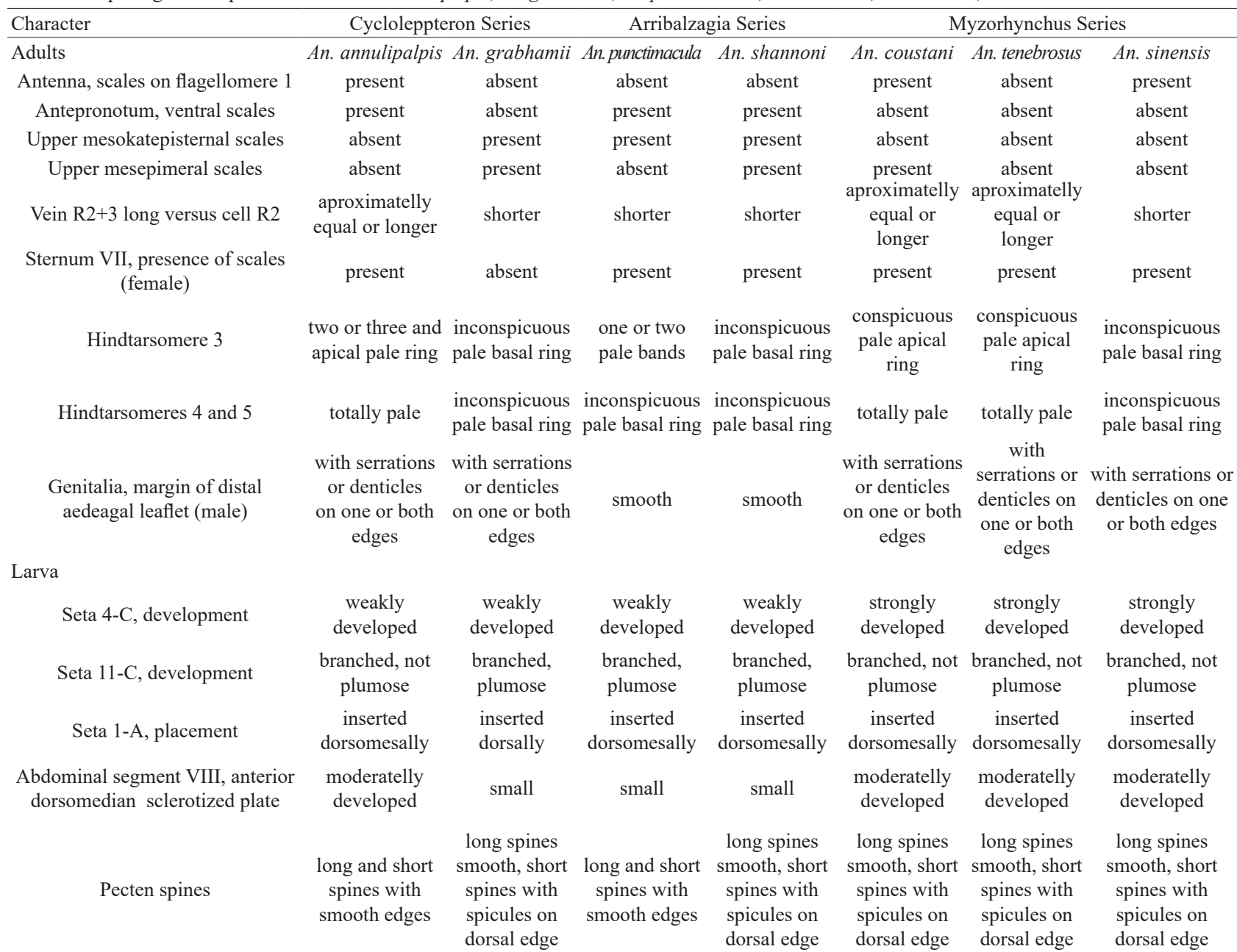

Pupa

Trumpet, development

Trumpet, meatal cleft(s)

Seta 5-V, development laticorn, tragus absent

present

similar to seta angusticom

gusticorn

absent

$1-\mathrm{V}$ laticorn, tragus laticorn, tragus latico

laticorn,

laticorn, traguss

absent tragus absent absent

present present present present

absent

$\begin{array}{lc}\text { similar to } & \text { similar to seta } \\ \text { seta } 1-\mathrm{V} & 1-\mathrm{V}\end{array}$ 
subgenus Anopheles. For this reason it is compared with $A n$. grabhamii (Cyclolepteron Series), An. punctimacula Dyar \& Knab, 1906, An. shannoni Davis, 1931 -Arribalzagia Series-, An. coustani Laveran, 1900, An. sinensis Wiedemann, 1828 and An. tenebrosus Donitz, 1902 of Myzorhynchus Series. Anopheles annulipalpis can be recognized in all its stages by combinations of certain morphological characters that separate species with which it was compared (Tab. III).

The subgenus Anopheles s. stricto includes 182 nominal species (HARBACH, 2014). EDWARDS (1932) proposed the first infrasubgeneric classification of Anopheles (Anopheles) and divided the subgenus into groups and series. REID \& KNIGHT (1961) adopted EDWARDS' (1932) classification and divided the subgenus into two sections, Angusticorn and Laticorn, and six series. The Laticorn Section includes the Arribalzagia, Christya, and Myzorhynchus Series, and the Angusticorn Section includes members of the Anopheles, Cycloleppteron, and Lophoscelomyia Series. The presence of a funnel-shaped pupal trumpet occurs on the members of the laticorn section, whereas those of the angusticorn possess a tubular pupal trumpet. Except for minor changes, the internal classification of the subgenus Anopheles s. stricto remains as it was proposed by REID \& KNIGHT (1961).

In his molecular study SALlum et al. (2002) conclude that the relationship among the Myzorhynchus, Arribalzagia and Anopheles Series remain unresolved because the present data do not provide unambiguous support for any relationhips. Moreover, the exact placement of subgenus Anopheles within genus Anopheles remains unresolved as a result of poor resolution of basal relationships within trees. HARBACH \& KicHTING (2005) found that the largest clade to branch from the main stem of the ordinal Anopheles consists of the Cycloleppteron Series in a sister-group relationship with the Arribalzagia plus Myzorhynchus Series. Collucci \& Sallum (2007) mentioned that An. annulipalpis and An. grabhamii of the Cycloleppteron Series did not group together, suggesting that the Series is not monophyletic. They considered the Myzorhynchus Series to be a paraphyletic assemblage, because it excluded species of the Arribalzagia and Christya Series, and An. annulipalpis of the Cycloleppteron Series.

HARBACH \& KICHTING (2015) considered that the Angusticorn and Laticorn Sections, the Anopheles and Cycloleppteron Series of the former and the Myzorhynchus Series of the latter are not monophyletic. The two species of the Cycloleppteron Series are unrelated, with An. annulipalpis sister to a clade comprised of the Coustani + Hyrcanus Groups.

Moreover, it is noteworthy that An. annulipalpis was not included in the phylogenetic analyses of the Anophelinae conducted by SAlLUM et al. (2002) and by HARBACH \& KICHTING (2005). In Collucci \& SAllum (2007) An. annulipalpis is included in the data set, although there are differences in the morphological characteristics of the data set and the ones observed here. Consequently, its position within Anopheles is uncertain. Based on the above and the presence of a laticorn trumpet, An. annulipalpis is removed from the Cycloleppteron series, however based on current cladistic analysis, $A n$. annulipalpis and An. grabhamii are clearly unrelated and the Cycloleppteron Series only includes An. grabhamii. According to HARBACH \& KiCHTING (2015) it is not possible to assign An. annulipalpis to an existing group, and they propose that the species must be retained in the Angusticorn Section as an unplaced species. Evidently, a complete re-assessment of the anopheline phylogeny is necessary.

Acknowledgements. The author want to thank Ralph Harbach for revising the manuscript and him and Ian Kitching for run the data set and confirm their non-membership to Cycloleppteron Series. To Ms. Monica Caviglia for the english revision.

\section{REFERENCES}

Alvarado, C. A. \& Del Ponte, E. 1938. Sobre la existencia de Anopheles annulipalpis en la provincia de Mendoza, R. A., descripción de su larva. Folia Biologica 90/93:388-389.

Belkin, J. N.; Heinemann, S. J. \& Page, W. 1970. The Culicidae of Jamaica (Mosquito Studies. XXI). Contributions American Entomological Institut 6:1-458.

Brèthes, J. 1912. Los mosquitos de la República Argentina. Boletín Instituto Entomología Patologia Vegetal 1:1-48.

Brèthes, J. 1916. Algunas notas sobre mosquitos argentinos. Anales del Museo Nacional de Historia Natural de Buenos Aires 28:93-218.

Campos, R. E. 1997. Comportamiento estacional de dos especies de Anopheles (Diptera: Culicidae) en la provincia de Buenos Aires. Revista Sociedad Entomologica Argentina 56:31-32.

Collucci, E. \& Sallum, M. A. M. 2007. Cladistic analysis of the subgenus Anopheles (Anopheles) Meigen (Diptera: Culicidae) based on morphological characters. Memorias Instituto Oswaldo Cruz 102:277-291.

Del Ponte, E. 1940. Descripción de la terminalia macho de Anopheles annulipalpis L. Arr. (Dipt. Culicidae). Revista Instituto Bacteriologico (Argentina) 9:602-603.

Dyar, H. G. 1928. The Mosquitoes of the Americas. Washington, Carneige Institution (Pub 387). 616p.

Edwards, F. W. 1932. Genera Insectorum. Diptera, Fam. Culicidae. Brussels, Desmet-Verteneuil, fascicle 194. 258p.

García, M. \& CASAL, O. H. 1964. Descripción de tres pupas de mosquitos neotropicales (Diptera: Culicidae). Revista Sociedad Entomologica Argentina 27:5-10.

Gillies, M. T. \& De Meillon, B. 1968. The Anophelinae of Africa south of the Sahara (Ethiopian zoogeographical region). 2ed. Johannesburg, South Africa Institut Medical Research. 343p.

HarbaCH, R. E. 1994. Review of the internal classification of the genus Anopheles (Diptera: Culcidae): the foundation for comparative systematics and phylogenetic research. Bulletin of Entomological Research 84:331-342.

HarbaCH, R. E. 2014. Mosquito Taxonomic Inventory. Available at $<$ http:// www.mosquito-taxonomic-inventory.info>. Accessed on October, 2014.

Harbach, R. E. \& Kitching, I. 2005. Reconsideration of anopheline mosquito phylogeny (Diptera: Culicidae: Anophelinae) based on morphological data. Systematic Biodiversity 3:345-374.

Harbach, R. E. \& Kitching, I. 2015. The phylogeny of Anophelinae revisited: inferences about the origin and classification of Anopheles (Diptera: Culicidae). Zoologica Scripta 45:34-47.

Harbach, R. E. \& KNight, K. L. 1980. Taxonomists' Glossary of Mosquito Anatomy. Marlton, Plexus Publishing. 415p.

Harbach, R. E. \& Knight, K. L. 1982. Corrections and additions to Taxonomists ' Glossary of Mosquito Anatomy. Mosquito Systematics 13:201-217.

Harrison, B. A. \& SCAnlon, J. E. 1975. Medical Entomology Studies II. The subgenus Anopheles in Thailand (Diptera: Culicidae). Contributions American Entomological Institut 12:1-308.

LANe, J. 1953. Neotropical Culicidae. vol. 1. São Paulo, Universidade de São Paulo. 548p. 
Lynch Arribálzaga, F. 1878. Descripcion de tres nuevos Culicidae de Buenos Aires. Naturalista Argentino 1:149-153.

Lynch Arribálzaga, F. 1891. Dipterologia Argentina. Revista Museo de La Plata 1:347-377.

ReID, J. A. \& KNIGHT, K. L. 1961. Classification within the subgenus Anopheles (Diptera: Culicidae). Annals Tropical Medicine Parasitology 55:475-489.

REINERT, J. F. 2009. List of abbreviations for currently valid generic-level taxa in family Culicidae (Diptera). European Mosquito Bulletin 27:68-76.

Romeo Viamonte, J. M. \& Castro, M. 1951. Estudio de la morfologia de la armadura faringea de algunos anofelinos. (Diptera: Culicidae). Revista Sanidad Higiene Pública 25:313-330.

Rossi, G. C.; Scheibler, E. \& Dominguez, M. C. 2006. Morphological description of the female, pupa, and larva of Culex (Culex) cuyanus Duret (Diptera: Culicidae). Zootaxa 1165:47-55.

Sallum, M. A. M.; Schultz, T. R.; Foster, P. G.; Aronstein, K.; Wirtzz, R. A. \& Wilkerson, R. C. 2002. Phylogeny of Anophelinae (Diptera
Culicidae) based on nuclear ribosomal and mitochondrial DNA sequences. Systematic Entomology 27:361-382.

Sallum, M. A. M.; Schultz, T. R. \& Wilkerson, R. C. 2000. Phylogeny of Anophelinae (Diptera Culicidae) based on morphological characters. Annals Entomological Society America 93:745-775.

Shannon, R. C. \& Del Ponte, E. 1928. Los Culicidos en la Argentina. Revista Instituto Bacteriologico (Argentina) 5:29-140.

Wilkerson, R. C. 1990. Redescriptions of Anopheles punctimacula and An. malefactor (Diptera: Culicidae). Journal Medical Entomology 27:225-247.

Wilkerson, R. C. \& Peyton, E. L.1990. Standarized nomenclature for the costal Wing spot of the genus Anopheles and other spotted wing mosquitoes (Diptera: Culicidae). Journal Medical Entomology 27:207-224.

Wilkerson, R. C.; Sallum, M. A. M. \& Foratini, O. P. 1997. Redescription of Anopheles (Anopheles) shannoni Davis; a member of the Arribalzagia Series from the Amazon Basin (Diptera: Culicidae). Proceedings of Entomological Society of Washington 99:461-471. 